\title{
Outcome of Eclamptic Mothers Attending Tertiary Care Centre from Home and those Referred from Primary Heath Care Site: A Comparative study
}

\author{
Upendra Pandit, ${ }^{\mathrm{a}, \mathrm{d}}$ Chittaranjan Das, ${ }^{\mathrm{b}, \mathrm{d}}$ Farhat Banu, ${ }^{\mathrm{c}, \mathrm{d}}$ Shakil Ahamad,e
}

\begin{abstract}
:
Introduction: Magnesium sulphate $\left(\mathrm{MgSO}_{4}\right)$ is an effective and safe drug which stabilizes the patient within few hours of eclampsia and terminates subsequent seizures if it is given on time. The aim of this study was to compare maternal and fetal outcome between a group of eclamptic mothers who came to the tertiary care hospital directly without receiving $\mathrm{MgSO}_{4}$ (Group 1) and those referred from primary care centers after receiving loading dose of $\mathrm{MgSO}_{4}$ (Group 2). Methods: This is a retrospective cohort study of eclamptic mothers who were admitted and managed from the period of $1^{\text {st }}$ January 2012 to $31^{\text {st }}$ March 2016 at Nepalgunj Medical College Teaching Hospital, Nepal. Sociodemographic characters and maternal and fetal outcome was compared between the two groups. Results: Among 92 cases, 57 (62\%) were from Group 1 and 35 (38\%) were from Group 2. Most of the mothers attended from Banke district $(n=52,56.5 \%)$ followed by Bardia district $(n=17,18.5 \%)$. Brahmin and Chhetri were $20(35 \%)$ and 10 (29\%); Muslim $16(28 \%)$ and four (11\%); Janajati from Terai $16(28 \%)$ and eight (23\%); Janajati from hilly region four (7\%) and five (14\%); and Chaudhari one (2\%) and eight (23\%) in Group 1 and Group 2 respectively. More $(n=26$, $74 \%)$ mothers had baby with good APGAR score in Group 2 than in Group $1(n=33,58 \%)$. There were $14(15.2 \%)$ still births; nine (16\%) in Group 1 and five (14\%) in Group 2. Complication rate was observed more in Group $1(n=16$, $28 \%)$ than in Group $2(n=7,20 \%)$ and the most common complication in both groups was wound infection. The mean days of hospital stay was $5.96(S D=3.32)$ and $5.91(S D=3.38)$ in Group 1 and Group 2 respectively. Conclusion: The group receiving magnesium sulphate in primary care centre have good fetal outcome and less maternal complications compared to those who were admitted directly in tertiary care centre and receive the treatment there.
\end{abstract}

Keywords: eclampsia $\bullet$ magnesium sulphate $\bullet$ seizure $\bullet$ treatment outcome

\section{INTRODUCTION:}

Eclampsia alone accounts for $30 \%$ of

\author{
a - Assistant Professor \\ b - Professor \\ c - Lecturer \\ d - Department of Obstetric and Gynecology \\ Nepalgunj Medical College Teaching Hospital, Nepal \\ e - Department of Pediatrics, \\ Nepalgunj Medical College Teaching Hospital, Nepal
}

Corresponding Author:

Dr. Upendra Pandit

e-mail: drupandit@gmail.com

How to cite this article:

Pandit U, Das CR, Banu F, Ahmad S. Outcome of eclamptic mothers attending tertiary care centre from home and those referred from primary heath care site: a comparative study. Journal of Lumbini Medical College. 2016;4(1):24-7. doi: 10.22502/jlmc.v4i1.79. maternal deaths in Nepal. ${ }^{1}$ The challenge behind it is the prevention and early detection of pre-eclamptic state in an antenatal mother. The management depends on the maternal conditions, gestational age, fetal wellbeing, cervical status and previous obstetric history. Foremost management approach is stabilization of an eclamptic mother and termination of the seizures and pregnancy. Magnesium sulphate $\left(\mathrm{MgSO}_{4}\right)$ is an effective and safe drug which stabilizes the patient within few hours of eclampsia and controls subsequent seizures if given on time. ${ }^{2}$

It is of utmost help if it can be given as soon as seizure develops. The number of seizures is one of the strongest determinants of poor feto-maternal outcomes. ${ }^{3}$ A hospital study found that the majority of women had the first fit at home (70.21\%), whereas 
approximately one fourth of them had it while already in the hospital (25.53\%). ${ }^{4}$

Ministry of Heath, Nepal, has made the provision of availability of $\mathrm{MgSO}_{4}$ in primary health care centre. Although there are different barriers in health care systems for the availability and utilization of magnesium sulfate for eclampsia, ${ }^{5}$ we have assumed that the eclamptic patients who are referred from primary care centre after receiving loading dose of $\mathrm{MgSO}_{4}$ on time i.e. immediately after first fit have better maternal and fetal outcomes than those patients who are brought directly to the referral centre without $\mathrm{MgSO}_{4}$ treatment. So the objective of this study was to compare the fetomaternal outcomes between these two groups.

\section{METHODS:}

This is a retrospective cohort study of eclamptic mothers who were admitted and managed at Nepalgunj Medical College Teaching Hospital (NGMCTH) which is a tertiary care hospital situated in Nepalgunj City in western Nepal. Patients from the districts of mid and far western region of the country are referred to this hospital for tertiary care. This hospital has well equipped intensive care facility for the management of obstetric emergencies.

Ethical approval and clearance were taken from hospital administration of NGMCTH and secondary data of all patients with eclampsia were collected from the period of $1^{\text {st }}$ January 2012 to $31^{\text {st }}$ March 2016. The eclamptic mothers who delivered in the hospital were included in this study. Cases of postpartum eclampsia were excluded from the study. These cases were divided into two groups. Group 1 was a group of eclamptic mothers who came to the tertiary care hospital without receiving $\mathrm{MgSO}_{4}$. Group 2 consisted of referred cases from primary care centers after receiving a loading dose of $\mathrm{MgSO}_{4}$.

Sociodemographic characters and maternal and fetal outcomes were compared between the two groups. The following variables were recorded: age, date and time of admission, referral card and details, address, gestational age, date, time and place of administration of loading dose of $\mathrm{MgSO}_{4}$ and the completion of its maintenance dose. Mode and time of delivery, APGAR score, birth weight and maternal and fetal morbidity and mortality were also recorded.

Data were tabulated and analyzed using IBM SPSS 20. Correlations of the variables were observed. A 95\% confidence interval and $p$ value of
$<0.05$ were considered as statistically significant. A chi-square test, Fisher exact test, and t-test were used to compare proportions and mean.

\section{RESULTS:}

Patient's characteristics: Among 92 cases, $57(62 \%)$ were brought directly in the tertiary care hospital (Group 1) and 35 (38\%) were brought from a primary care center (Group 2). Group 1 received $\mathrm{MgSO}_{4}$ only after they reached the hospital. Thirty five $(38 \%)$ patients were referred with a referral note from the primary care centre after receiving loading dose of $\mathrm{MgSO}_{4}$. The mean age of all patients was $20.79 \mathrm{yr}(S D=3.3)$. The most common age group was $20-24$ yr ( $n=32,56 \%$ and $n=21,60 \%)$ followed by the age group $15-19$ yr $(n=19,33 \%$ and $n=8$, 23\%) in group 1 and group 2 respectively. There were no significant differences between the two cohorts regarding age, gestational age, and mode of delivery (Table 1$)$. The mean gestational age was $37.2 \mathrm{yr}(S D=2.2)$ and $37.2 \mathrm{yr}(S D=2.1)$ in Group 1 and Group 2 respectively.

Table 2 shows the frequency distribution of cases in each group according to the district from where they were brought. Most patients were from Banke district followed by Bardia district.

By ethnic group, Brahmin and Chhetri together were 20 (35\%) and 10 (29\%); Muslim were $16(28 \%)$ and four (11\%); Janajati from Terai were 16 (28\%) and eight (23\%); Janajati from hilly region were four (7\%) and five (14\%); and Chaudhari were one (2\%) and eight (23\%) in Group 1 and Group 2 respectively.

The most common gravidity of

Table 1.Distribution of characteristics of eclamptic mothers

\begin{tabular}{|c|c|c|c|}
\hline Variables & Group One & Group Two & \\
\hline Maternal Age (years) & $n(\%)$ & $n(\%)$ & \multirow{4}{*}{$\begin{array}{c}X^{2}=1.6 \\
\mathrm{df}=2 \\
\mathrm{p}=0.46\end{array}$} \\
\hline $15-25$ & $19(33)$ & $8(23)$ & \\
\hline $20-24$ & $32(56)$ & $21(60)$ & \\
\hline 25-Above & $6(11)$ & $6(17)$ & \\
\hline \multicolumn{4}{|l|}{ Gestational Age } \\
\hline$<37$ & $25(44)$ & $10(29)$ & \multirow{2}{*}{$\begin{array}{c}X^{2}=2.2 \\
\mathrm{df}=1 \\
\mathrm{p}=0.19\end{array}$} \\
\hline$\geq 37$ & $32(56)$ & $25(71)$ & \\
\hline \multicolumn{4}{|l|}{ Mode of Delivery } \\
\hline Vaginal delivery & $9(16)$ & $5(14)$ & \multirow{3}{*}{$\begin{array}{l}p=1 \\
F E T\end{array}$} \\
\hline $\begin{array}{l}\text { Instrumental } \\
\text { delivery }\end{array}$ & $4(7)$ & $2(6)$ & \\
\hline CS & $44(77)$ & $28(80)$ & \\
\hline
\end{tabular}


Table 2: Distribution of Eclamptic patients according to address.

\begin{tabular}{ccc}
\hline Districts & $\begin{array}{c}\text { Group 1 } \\
n(\%)\end{array}$ & $\begin{array}{c}\text { Group 2 } \\
n(\%)\end{array}$ \\
\hline Banke & $45(79)$ & $7(20)$ \\
Bardiya & $3(5.3)$ & $14(40)$ \\
Kailali & $3(5.3)$ & $5(14)$ \\
Dang & $3(5.3)$ & $5(14)$ \\
Salyan & 0 & $2(6)$ \\
Others & $3(5.3)$ & $2(6)$ \\
\hline Total & $\mathbf{5 7 ( 1 0 0 )}$ & $\mathbf{3 5 ( 1 0 0 )}$ \\
\hline
\end{tabular}

eclamptic mothers was primary gravida ( $n=44$, $77.1 \%$ and $n=26,74.2 \%$ in Group 1 and two respectively). The other mothers in each group were multi gravida and the difference was statistically not significant $\left(X^{2}=0.1, d f=1, p=0.8\right)$.

The most common $(n=72,78.3 \%)$ mode of delivery in eclamptic mothers was caesarean section (CS). Among them, 44 (61.1\%) mothers underwent CS in Group 1 and 28 (38.8\%) in Group 2. There was no significant difference in mode of delivery between the two groups $\left(X^{2}=0.1, d f=1, p=0.8\right)$.

There were $13(14.1 \%)$ still births. Most of them ( $n=8,61.5 \%)$ belonged to Group 1 .The live birth rate in the two groups was 49 (86\%) and 30 $(86 \%)$ respectively and the difference was not statistically significant.

Table 3 shows that approximately $74 \%$ of mothers had a baby with good APGAR score in Group 2 compared to one (58\%) in Group 1. Maternal outcome, as live, was observed in 56 (98.3\%) and 34 (97\%) in Group 1 and Group 2 respectively. There was one maternal death in each group. No significant difference was observed maternal mortality in both the groups.

Table 4 shows that the maternal complication rate was observed more in Group $1(n=16,28 \%)$ than in Group $2(n=7,20 \%)$. though not statistically significant $\left(X^{2}=0.75, d f=1, p=0.46\right)$. The most common complication was wound infection in both groups.

The mean days of hospital stay were 5.96 days $(S D=3.32)$ and 5.91 days $(S D=3.38)$ in Group 1 and Group 2 respectively. No significant difference was observed in terms of hospital stay in the two groups ( $t=.07, d f=90, p=0.94)$.

\section{DISCUSSION:}

Eclamptic mothers attending tertiary care centre directly from home (Group l) were higher in number $(n=57,62 \%)$ than referral group $(n=35$, $38 \%$ ). Amongst them, most cases attended from Banke district. Banke and Bardia are home and neighboring districts respectively from tertiary care centre. It shows that high prevalence of eclampsia diseases occurs in Banke district. Preventive as well as early detection campaign is needed in those districts as an outreach antenatal care program.

Most of the mother with eclampsia from Muslim and Janajati community in Bake and Bardia districts were admitted directly in tertiary care centre. It may be due to unavailability of the primary care centre or simply the ignorance and unawareness of primary facilities available in the community.

Table 3: APGAR score according to the admission status

\begin{tabular}{cccc}
\hline Variables & Group l & Group ll & $\boldsymbol{P}$ \\
\hline APGAR score & $n(\%)$ & $n(\%)$ & \\
0 & $9(16)$ & $5(14)$ & \\
$1-3$ & $0(0)$ & $1(3)$ & \\
$4-6$ & $15(26)$ & $3(9)$ & \\
$>7$ & $33(58)$ & $26(74)$ & \\
Maternal outcome & & & \\
Live & $56(98.3)$ & $34(97)$ & $p=1$ \\
Death & $1(1.7)$ & $1(3)$ & $F E T$ \\
\hline
\end{tabular}

Table 4: Maternal complications according to the admission status

\begin{tabular}{lcc}
\hline Maternal Complications & $\begin{array}{c}\text { Group I } \\
n(\%)\end{array}$ & $\begin{array}{c}\text { Group 2 } \\
n(\%)\end{array}$ \\
\hline Present & $16(28)$ & $7(20)$ \\
Postpartum Hemorrhage & $6(10)$ & $2(6)$ \\
Wound infection & $8(14)$ & $3(8)$ \\
Pulmonary Edema / & $1(2)$ & $2(6)$ \\
Respiratory failure & $1(2)$ & 0 \\
\hline Acute renal failure & $41(72)$ & $28(80)$ \\
\hline Absent & &
\end{tabular}

The rate of still birth was observed more in Group 1 than in Group 2. The still birth rate is slightly higher compared to the findings in Ethiopia by Eshetu S. et al. ${ }^{6}$ Out of 14 still births, 7 (53.8\%) were from Banke district from where majority of mother attended hospital directly from home for the treatment of eclampsia.

CS was the commonest mode of delivery in both the groups, $44(77.1 \%)$ mothers underwent CS in Group 1 and 28 (80\%) in Group 2 respectively. 
The CS rate was slightly higher in Group 2 and the overall CS rate is high compared to the CS rate of $45.8 \%$ among eclampsia patients in one of the retrospective study done by Abate $\mathrm{M}$. et al. ${ }^{7}$ There was no significant difference in the mode of delivery in both groups $(p=0.79)$. The mode of delivery did not differ in patients who received $\mathrm{MgSO}_{4}$. If immediate caesarean delivery is conducted, the maternal and fetal outcome is good in eclampsia. ${ }^{8}$

Approximately $74.2 \%$ of mothers had a baby with good APGAR score in group 2 compared to that in group $1(57.8 \%)$. There were $14(15.2 \%)$ still births in total and majority of them $(n=9,61.5 \%)$ were from Group l. This suggests that the mothers who attended the hospital directly were probably unable to receive $\mathrm{MgSO}_{4}$ in time, so the better fetal outcome was observed in referred mothers.

Complication rate was observed more in Group 1 (28\%) than in Group 2 (20\%). The case fatality rate collectively in both groups was observed at $17.3 \%$ which is higher compared to the tertiary

\section{REFERENCES:}

1. Ministry of Health and population (MoHP) [Nepal]. Annual Report of the Department of Health Services Kathmandu, Government of Nepal; 2014.

2. Cipolla MJ, Kraig RP. Seizures in Women with Preeclampsia: Mechanisms and Management. Fetal Matern Med Rev. 2011 May; 22(02):91-108. doi: 10.1017/ S0965539511000040.

3. The Eclampsia Trial Collaborative Group. Which anticonvulsant for women with eclampsia? Evidence from the Collaborative Eclampsia Trial. Lancet. 1995;345:1455-63.

4. Choudhary P. Eclampsia: a hospital based retrospective study. Katmandu Univ Med J (KUMJ). 2003;1(4):237-41.

5. Lotufo FA, Parpinelli MA, Osis MJ, Surita FG, Costa ML, Cecatti JG. Situational analysis of facilitators and barriers to availability and utilization of magnesium sulfate for eclampsia and severe preeclampsia in the public health system in Brazil. BMC Pregnancy Childbirth. 2016;16(1): 254. doi:10.1186/s12884-016-1055-0. care hospitals in Tanzania (7.7\%). ${ }^{9,10}$

We recommend encouragement and promotion of the use of $\mathrm{MgSO}_{4}$ in a primary care centre, especially in Banke and Bardia districts, to mothers with eclampsia immediately after fits.

\section{CONCLUSION:}

Mothers with eclampsia who received $\mathrm{MgSO}_{4}$ in primary care centre have good fetal outcome and less maternal complications compared to those that attend tertiary care centre directly and receive the treatment there. Loading dose of $\mathrm{MgSO}_{4}$ if given immediately after initial convulsion at a primary health facility before referral, is beneficial to improve the maternal and fetal outcome.

\section{DISCLOSURE:}

No conflict of interest declared.

No violation of human rights and safety.

No fund available for this study.

6. Eshetu S, Mubarak A, Million T, Netsanet F, Maternal and fetal outcome of pregnancy related hypertension in Mettu Karl Referrel Hospital, Ethiopia. Journal of Ovarian Research. 2015;8:10. doi 10.1186/s13048-015-0135-5.

7. Abate M, Lakew Z. Eclamsia a 5 years retrospective review of 216 cases managed in two teaching hospitals in Addis ababa. Ethiopian medical journal. 2006;44(1):27-31.

8. Coppage $\mathrm{KH}$, Polzin WJ. Severe preeclampsia and delivery outcomes: is immediate cesarean delivery beneficial? Am J Obstet Gynecol. 2002 May;186(5):921-3.

9. Kidanto HL, Mogren I, Massawe SN, Lindmark G, Nystrom L. Criteria based audit on management of eclampsia patients at a tertiary hosital in Dar es Salaam, Tanzania. BMC Pregnancy and Childbirth. 2009;9(13):1-9.

10. Jido TA. Eclampsia: maternal and fetal outcome. Afr Health Sci. 2012 Jun;12(2):148-52. 